\title{
The Relationship Between Drawing Stereotypic Images and Female Students' Science Learning Motivation
}

\author{
Chin-Fei Huang, Ching-Sen Shih, Guang-Jing Chen, Chia-Ju Liu \\ National Kaohsiung Normal University, Kaohsiung, Taiwan
}

\begin{abstract}
The purpose of this study was to examine female students' science learning motivation by drawing stereotypic images. Some previous studies found that female students consistently underperform compared to male students on science and a lot of female students in senior high school had negative thinking about science learning. Since the female students have negative thinking about science, most of them have stereotypic images in many careers about science. There is a distinct gender gap in science achievement scores of male and female high school students, as proposed in many researches. One hundred female students of senior high schools participated in this study to draw their stereotypic images and write down the Science Motivation Test. This study asked female students to draw "a scientist," "a science teacher," "a doctor," and "a nurse" by their own impression, and then, they need to write the Science Motivation Test. The Cronbach's $\alpha$ of this test is 0.86 . The results showed that $44 \%$ female students draw "males" as "doctors" and 28\% female students draw "females" as "doctors." Besides, $66 \%$ female students draw "females" as "nurses." The results indicated that the female high school students still had solid stereotypic images of career. Furthermore, lower than 30\% female students draw "females" as "scientists," and there are about $40 \%$ female students draw "females" as "science teachers." Besides, the female students who draw "females" as "scientists" showed higher science learning motivation. However, the female students who draw "females" as "science teachers" did not show the trend of science learning motivation. This study attempts to explain the reasons for these differences.
\end{abstract}

Keywords: gender, stereotypic images, science learning motivation

\section{Introduction}

In 2015, the analyzed data from National Student Clearinghouse Research Center $^{1}$ indicated that high school female students got lower motivation and participation in science research. In the statistically analyzing data, the undergraduate science and engineering degree of women was less than $20 \%$ for engineering and less than $40 \%$ for earth and physical science. In other words, less female students wanted to join to study science subjects, and it can be imagined that they would not choose the jobs about science to be their career.

The same situations are also shown in the past studies. In Weinburgh's (1995) study, the meta-analysis

Chin-Fei Huang, Ph.D., assistant professor, Graduate Institute of Science Education \& Environmental Education, National Kaohsiung Normal University.

Ching-Sen Shih, Ph.D. candidate, Graduate Institute of Science Education \& Environmental Education, National Kaohsiung Normal University.

Guang-Jing Chen, Master Student, Graduate Institute of Science Education \& Environmental Education, National Kaohsiung Normal University.

Chia-Ju Liu, Ph.D., professor, Graduate Institute of Science Education \& Environmental Education, National Kaohsiung Normal University.

${ }^{1}$ For more information, please visit http://nscresearchcenter.org/. 
data dealing with gender and attitude towards science reported that boys have a more positive motivation towards science than girls. A distinct gap from gender is shown in the achievement scores in math and science subjects, as well as be shown in the decision-making when they choose career fields (Kahle \& Lakes, 1983; Keller \& Dauenheimer, 2003; Rachel \& Jean, 2012). Despite decades of active recruitment, women remain eliminate to major in science, technology, engineering, and math (STEM) disciplines both in the United States (U.S.) and globally. Women leave STEM fields at all stages of their careers - as undergraduates, graduate students, professionals, and in the transition between each stage (Lauer, Momsen, Offerdahl, Kryjevskaia, Christensen, \& Montplaisir, 2013). The gender gap often does not only emerge until high school, but also lead to their choice of career (Bleeker \& Jacobs, 2004; Marx \& Roman, 2002).

Why female students do not like science? The lack of learning motivation will be the answers. Many past researches mentioned that motivation is one of the key points to promote students' learning and activities (Hynd, Holschuh, \& Nist, 2000; Pintrich, 2003). No matter what goals people want to reach, the motivation would be the most important factor to lead people go. In the same way, the key point to promote students' active learning and learning achievement is learning motivation. Therefore, to find the learning strategies to promote students' learning motivation and provide students' extensive willpower to learn science is a core issue in science education.

Why do female students get lower learning motivation in science? Students' negative thinking of the stereotype about science and scientists might be the reasons. Previous studies argued that a lot of students described that the majority of students in all age lines drew elderly-aged male scientists wearing lab coats and glasses with facial hair and doing research indoors with chemicals (Akcay, 2011; Chambers, 1983; Finson, 2002; Turkmen, 2008), that is we call the stereotype. Schibeci and Sorensen (1983) mentioned that the stereotype about scientists in elder students became more immovably than younger students. Hsu and Yang (1998) also found that personal image about scientists reflects students' thinking about science learning value and motivation. Further, recently, some studies mentioned stereotypic images may influence students' performance of science comprehension on male and female high school students, and those stereotypic images could influence the gender differences in science learning (Miyake, Kost-Smith, Finkelstein, Pollock, Cohen, \& Ito, 2010). To sum up, it is very important to know well female students' thinking of science and scientists, and to investigate the correlation between students' thinking of stereotype and learning motivation is also an important and urgent research.

Therefore, the purpose of this study is to investigate the female students' science learning motivation by drawing stereotypic images. Then, the qualitative and quantitative data will be analyzed to interpret the correlation between students' thinking of stereotype and learning motivation.

\section{Method}

\section{Research Design}

This study aimed to explore the female students' science learning motivation by drawing stereotypic images. There are three steps in the research design (see Figure 1). First, the participants needed to draw four pictures to show their stereotype of science and the career about science. Second, they needed to write down a Science Motivation Scale. Third, they needed to be interviewed randomly.

As Figure 1 shows, there are three steps in the research design of this study. The details will be illustrated below. 


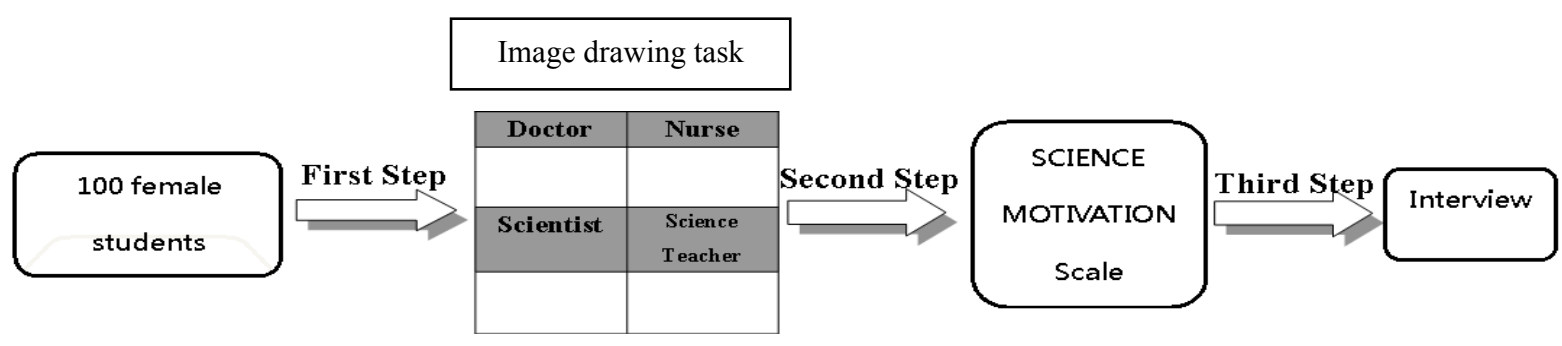

Figure 1. The research design in this study.

\section{Participants}

One hundred 11th to 12th grade female students $(N=100$; Mean age $\pm \mathrm{SD}=17.2 \pm 1.3$ years $)$ were recruited in this study. All of them are senior high school students. Some of them are majored in social trend subjects and the others are majored in science trend subjects. All of these students learned about the foundation science subjects, such as physics, chemistry, and biology, in 7th to 10th grade, and they chose to be majored in social trend subjects or science trend subjects by themselves at the start of 11th grade.

\section{Instruments}

There are three instruments in this study. The first one is the image drawing task, the second is the Science Motivation Scale, and the third is interview. The details are as follows.

Image drawing task. In the image drawing task, the students were asked to draw four pictures about "a doctor," "a nurse," "a scientist," and "a science teacher" in the drawing picture paper which provided in this study.

Science Motivation Scale. The learning motivation scale (Likert scale) was developed by some of the authors which was published in 2012 (Huang \& Liu, 2012). The scale reached into the expert reliability and the validity reached into $\alpha=0.86$. There are seven items in this scale and the total scores are 120 scores. There are four dimensions in the learning motivation scale which involved self-efficacy, goals of performance, the values of learning, and the sense of achievements. The participants needed to write down this scale after drawing the image task.

Interview. The participants were been interviewed randomly by the authors. The outline of interview contents included:

1. Why did you draw these pictures in male/female/other gender?

2. Do you think males/females could do this job (doctor/nurse/scientist/science teacher) more competently? Why?

3. Could you like science? Why?

4. Do you believe you can be a doctor/nurse/scientist/science teacher? Why?

\section{Data Collection and Analysis}

The participants' drawing pictures and scores of the Science Motivation Scale were collected for analysis. The extracted data were analyzed using statistical analysis. The interview data were used to know well the participants' detail thoughts.

\section{Results}

In this study, three steps were designed to know well the female students' science learning motivation by drawing stereotypic images, which included image drawing task step, Science Motivation Scale writing step, and interview step. 
In the first step, the drawing pictures were collected and the different gender images in these pictures were calculated. Three kinds of images were categorized in this study. The first category is male image, the second is female image, and the third is other image. If the students did not show the obvious gender image or show the male and female image both in one drawing pictures, that picture will be categorized into "other" (see Figure 2).

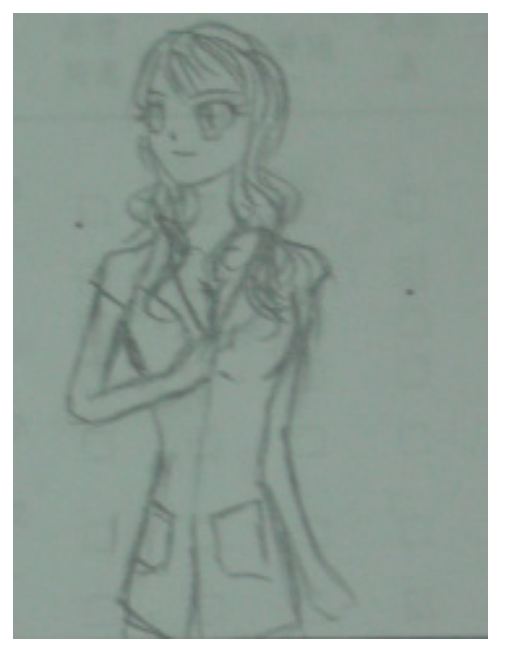

(a)

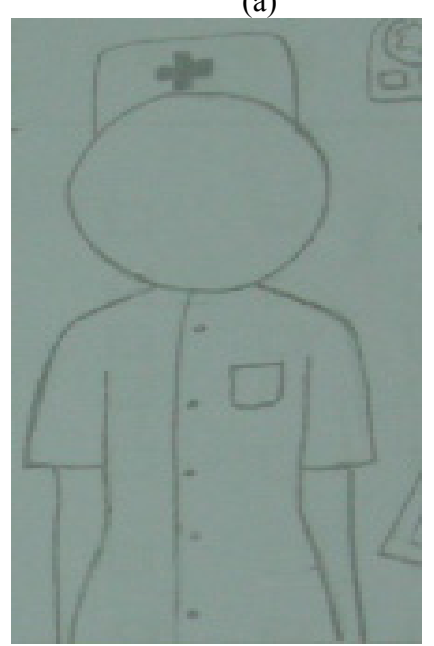

(c)

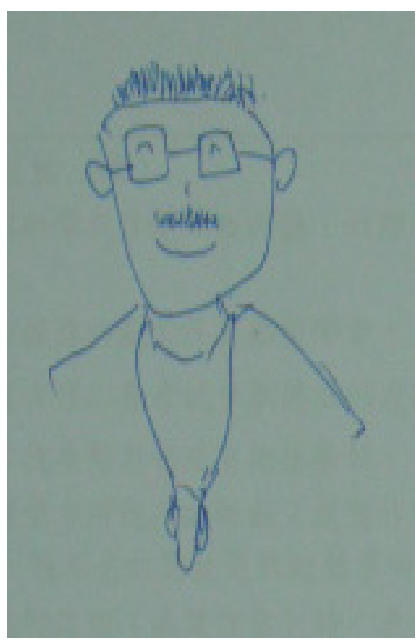

(b)

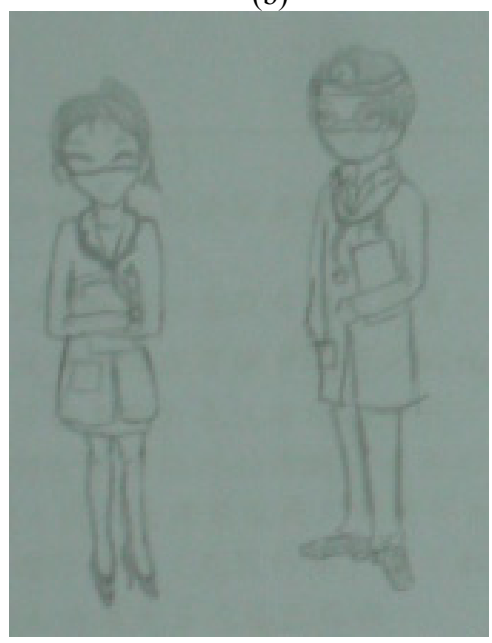

(d)

Figure 2. The categories of gender images: (a) female image; (b) male image; and (c) (d) other image.

The analyzed data from the three gender categories showed that the female students got obviously thinking of stereotype in the career of science and scientists (see Table 1), especially in the image about nurse.

Table 1

The Data of Stereotype Categories From Drawing Pictures $(N=100)$

\begin{tabular}{|c|c|c|c|c|c|c|c|c|c|c|c|c|}
\hline & \multicolumn{3}{|c|}{ Doctor image } & \multicolumn{3}{|c|}{ Nurse image } & \multicolumn{3}{|c|}{ Scientist image } & \multicolumn{3}{|c|}{ Science teacher image } \\
\hline & Male & Female & Other & Male & Female & Other & Male & Female & Other & Male & Female & Other \\
\hline Participants & 44 & 25 & 31 & 6 & 66 & 28 & 46 & 28 & 26 & 30 & 37 & 33 \\
\hline
\end{tabular}

As Table 1 shows, in this study, $44 \%$ female students thought doctors as male image, $66 \%$ female students thought nurses as female image, and $46 \%$ of them thought scientist as male image. However, the stereotype thinking is not been found in the science teacher image. 
Besides, in the participants' drawing, the stereotype of scientists included "strange looks," "doing experiment all the time," and "dirty face with dishevelled hair" (see Figure 3).

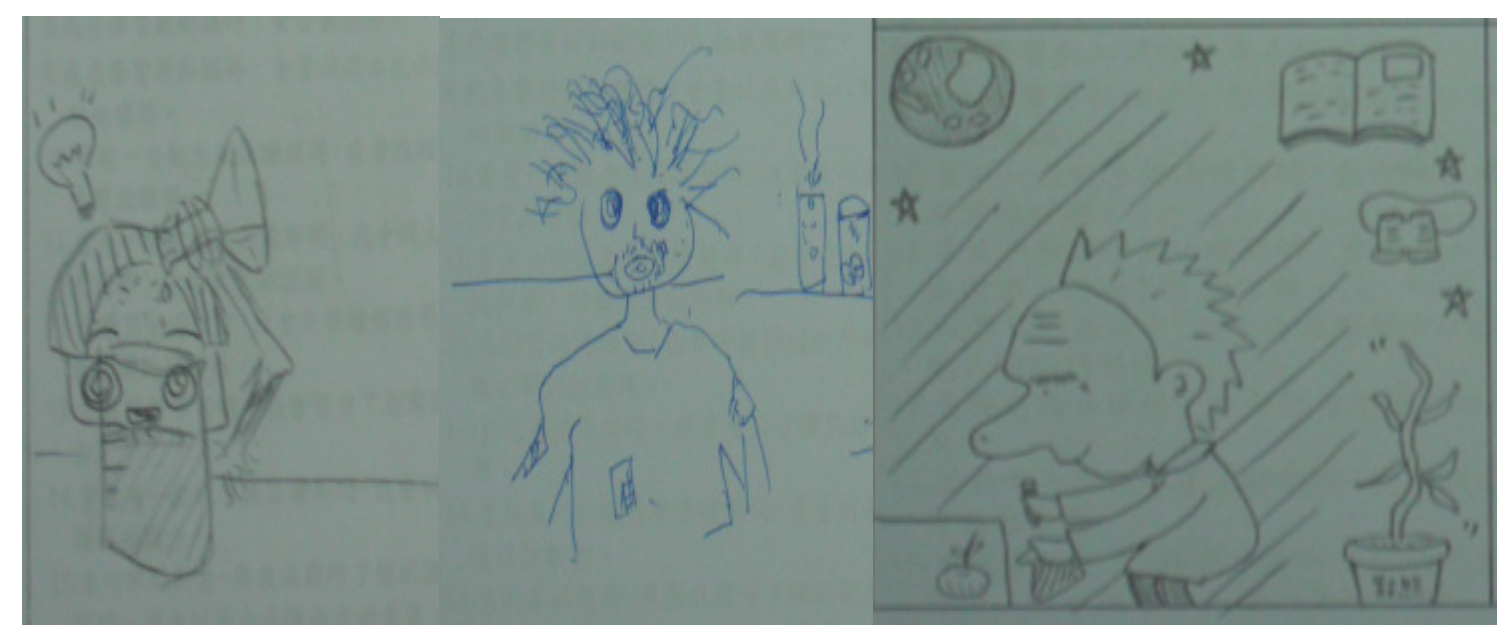

Figure 3. The stereotype of scientists included "strange looks," "doing experiment all the time," and "dirty face with dishevelled hair."

To analyze the correlation between stereotype image and science learning motivation, the findings in this study indicated that the participants got higher science learning motivation than others when they draw the doctor as female image (see Figure 4[a]). Similarly, the participants got higher science learning motivation than others when they draw the nurse as female image (see Figure $4[b]$ ). Besides, there are no significantly differences of participants' science learning motivation between three gender categories of science teacher image (see Figure 5). At last, the participants got higher science learning motivation both in drawing scientists as male and female image than other image (see Figure 6).

The findings from Figures 4(a), 4(b), 5, and 6 may indicate that the female students' science learning motivation would not correlate with the stereotypic image of scientists and science teachers, but correlate with the professional career of scientific trend. The "future career" might be the key point to influence female students' science learning motivation. If the female students do not believe that they have the competency to do some scientific trend professional jobs, they may give up learning science.

\section{Doctor Image}

Science Learning Motivation

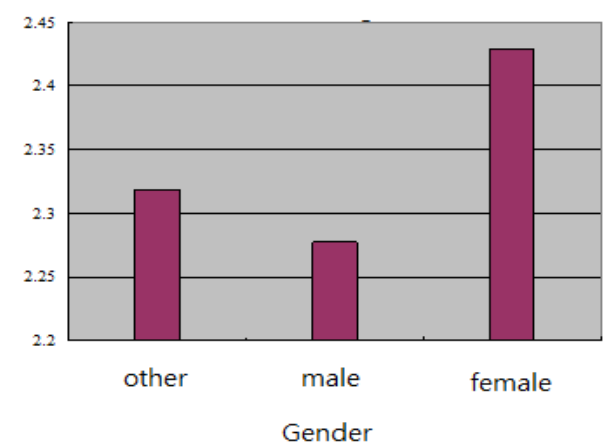

(a)

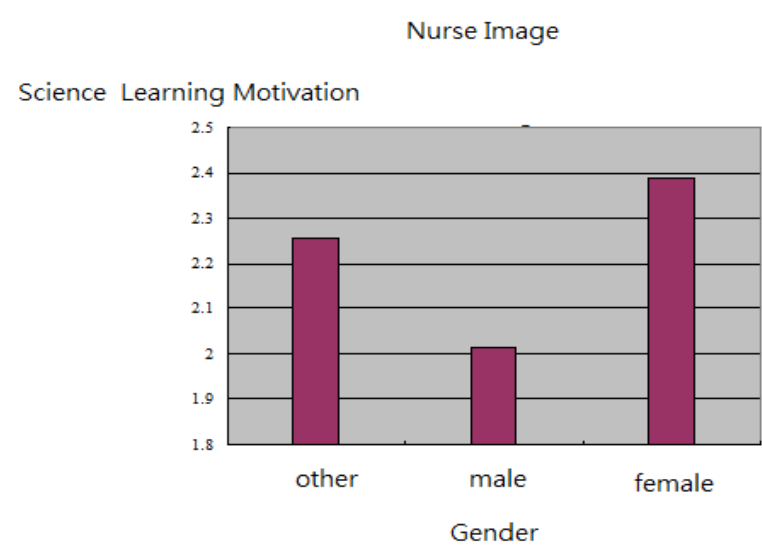

(b)

Figure 4. The participants: (a) got higher science learning motivation when draw the doctor as female image; (b) got lower science learning motivation when draw the nurse as male image. 


\section{Science Teacher Image}

\section{Science Learning Motivation}

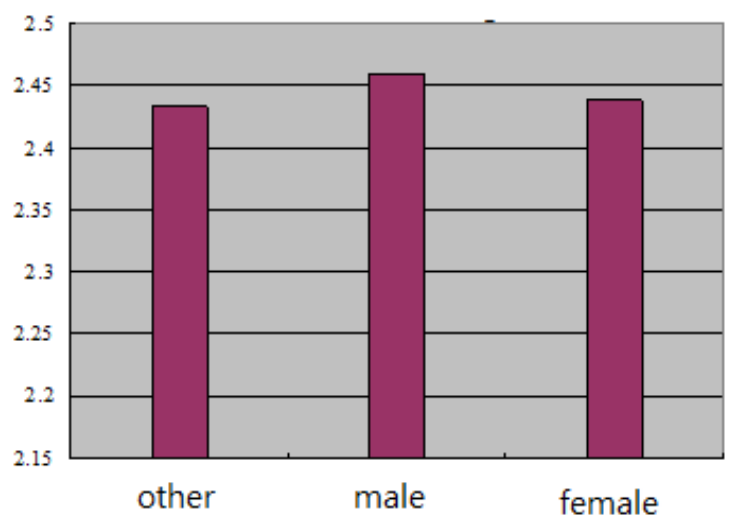

Gender

Figure 5. The participants' science learning motivation between three gender categories of science teacher image.

\section{Science Teacher Image}

Science Learning Motivation

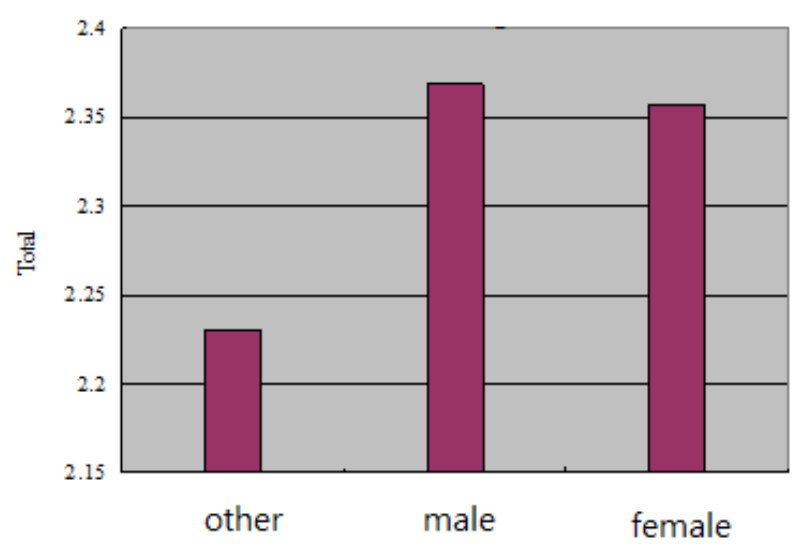

Gender

Figure 6. The participants' science learning motivation between three gender categories of scientists.

Although this study provides the findings about the correlation between stereotype and science learning motivation, the data from Figure 4 to Figure 6 showed important and serious information. The data from Figure 4 to Figure 6 showed that the female students' science learning motivations are all lower than 2.5 point. Based on the Likert's scales, the total scores from Science Motivation Scale are 5 point. The results showed that the female students got lower science learning motivation no matter what kind of stereotype they have. Also, both the senior high female students major in social trend and science trend got lower science learning motivation in this study. That is an important warning sign that all of us should focus on immediately. 


\section{Discussion and Conclusion}

From the data analysis of this study, we can find senior high school female students who get stereotype about doctors and nurses as females get higher science learning motivation. Female students who get stereotype about scientists as males or females get the similar science learning motivation. Then, female students did not have stereotype about science teacher image. The interview data indicated that students' drawing about science teacher influences on school teachers, and both of male and female science teachers are shown in their school.

According to the study, indeed, most people believe that mathematics, physics, chemistry, engineering, and science is more suitable for male, less for women studies disciplines or career occupation (Oswald \& Harvey, 2003; Shin, Lee, McCarthy-Donovan, Hwand, Yim, \& Seo, 2015). In fact, fewer women than men select science-related courses or put into science related fields of its occupation (Betz \& Hackett, 1981). Nation Science Foundation of U.S. statistics in 2000 also found that among the graduates in mathematics, physics, computers, and other departments, women make up only $35 \%$.

"Gender stereotype" mainly refers to the "Men and women are different" perception, meaning people for men and women should have what qualities, what performance behavior, even what kind of job, the insurance some holders of fixed stereotype and perception. Usually, it is not necessarily a gender stereotype entirely correct, but deeply rooted in the community among members and between different members of the group have the consistency or universality.

The gender differences in science are due to the differences in motivations and attitudes that come from socialization and not from abilities (Tyler-Wood, Ellison, Lim, \& Periathiruvadi, 2012). Therefore, it is important to provide educational interventions to decrease students' gender stereotype and encourage females to form positive attitudes to science-related jobs. In this study, we found that the main stereotype which influences students' science learning motivation might be their attitudes to science-related jobs. This study suggested that further studies be conducted to explore the relationship between stereotype and science learning motivation in lower grade students. The kindergarten to 9 th grade students might be not influenced by the thoughts of future jobs. The lower grade students may show different results from senior high school students.

\section{References}

Akcay, B. (2011). Turkish elementary and secondary students' views about science and scientist. Asia-Pacific Forum on Science Learning and Teaching, 12(1), 1-11.

Betz, N. E., \& Hackett, G. (1981). The relationship of career-related self-efficacy expectations to perceived career options in college women and men. Journal of Counseling Psychology, 28(5), 399-410.

Bleeker, M. M., \& Jacobs, J. E. (2004). Achievement in math and science: Do mothers' beliefs matter 12 years later? Journal of Educational Psychology, 96(1), 97-109.

Chambers, D. W. (1983). Stereotypic images of the scientist: The Draw-A-Scientist Test. Science Education, 67(2), 255-265.

Finson, K. D. (2002). Drawing a scientist: What we do and do not know after fifty years of drawings. School Science and Mathematics, 102(7), 335-345.

Hsu, P. L., \& Yang, W. G. (1998). Print and image integration of science texts and reading comprehension: A systemic functional linguistics perspective. International Journal of Science and Mathematics Education, 5(4), 639-659.

Huang, C. F., \& Liu, C. J. (2012). Exploring the influences of elementary school students' learning motivation on Web-based collaborative learning. US-China Education Review, 2(7), 613-618.

Hynd, C., Holschuh, J., \& Nist, S. (2000). Learning complex scientific information: Motivation theory and its relation to student perceptions. Reading \& Writing Quarterly: Overcoming Learning Difficulties, 16(1), 23-57.

Kahle, J. B., \& Lakes, M. K. (1983). The myth of equality in science classrooms. Journal of Research in Science Teaching, 20(2), 131-140. 
Keller, J., \& Dauenheimer, D. (2003). Stereotype threat in the classroom: Dejection mediates the disrupting threat effect on women's math performance. Personality and Social Psychology Bulletin, 29(3), 371-381.

Lauer, S., Momsen, J., Offerdahl, E., Kryjevskaia, M., Christensen, W., \& Montplaisir, L. (2013). Stereotyped: Investigating gender in introductory science courses. CBE-Life, Sciences, Education, 14(3), 30-38.

Marx, D. M., \& Roman, J. S. (2002). Female role models: Protecting Women's math test performance. Personality and Social Psychology Bulletin, 28(9), 1183-1193.

Miyake, A., Kost-Smith, L. E., Finkelstein, N. D., Pollock, S. J., Cohen, G. L., \& Ito, T. A. (2010). Reducing the gender achievement gap in college science: A classroom study of values affirmation. Science, 330(6008), 1234-1237.

Oswald, D. L., \& Harvey, R. D. (2003). A Q-methodological study of women's subjective perspectives on mathematics. Sex Roles, 49(3-4), 133-142.

Pintrich, P. R. (2003). A motivational science perspective on the role of student motivation in learning and teaching contexts. Journal of Educational Psychology, 95(4), 667-686.

Rachel, A. L., \& Jean, M. M. (2012). The differences in scores and self-efficacy by student gender in mathematics and science. International Journal of Science and Mathematics Education, 10(5), 1163-1190.

Schibeci, R. A., \& Sorenson, I. (1983). Elementary school children's perceptions of scientists. School Science and Mathematics, 83(1), 14-19.

Shin, J., Lee, H., McCarthy-Donovan, A., Hwang, H., Yim, S., \& Seo, E. (2015). Home and motivational factors related to science-career pursuit: Gender differences and gender similarities. International Journal of Science Education, 37(9), 1478-1503.

Turkmen, H. (2008). Turkish primary students' perceptions about scientist and what factors affecting the image of the scientists. Eurasia Journal of Mathematics, Science \& Technology Education, 4(1), 55-61.

Tyler-Wood, T., Ellison, A., Lim, O., \& Periathiruvadi, S. (2012). Bringing up girls in science (BUGS): The effectiveness of an afterschool environmental science program for increasing female students' interest in science careers. Journal of Science Education and Technology, 21(1), 46-55.

Weinburgh, M. (1995). Gender differences in student attitudes toward science: A meta-analysis of the literature from 1970 to 1991. Journal of Research in Science Teaching, 32(4), 387-398. 